\title{
El crédito hipotecario y el acceso a la vivienda para los hogares de menores ingresos en América Latina
}

\author{
Gerardo M . Gonzales Arrieta
}

$\mathrm{B}$

asándose en un estudio sobre las opciones de crédito hipotecario disponibles en ocho países latinoamericanos, el artículo identifica dos tareas pendientes para la mayoría de los países: la necesidad de movilizar recursos de largo plazo para mitigar los riesgos de descalce de plazos y de tasas, y la necesidad de armonizar los criterios de rentabilidad para los prestamistas con el criterio de acceso al crédito para la población con bajo poder adquisitivo. Recomienda crear vínculos entre el mercado financiero de vivienda y el mercado de capitales a través de mercados secundarios de hipotecas, para lo cual es preciso que el sistema financiero de vivienda utilice instrumentos aislados de subsidios. Asimismo, propone una serie de opciones a fin de que la participación del Estado contribuya a formar mercados hipotecarios y a dar mayor acceso a la vivienda a la población de menores ingresos. 


\section{I}

\section{Introducción}

El financiamiento de la vivienda es un elemento central de toda política habitacional. Por lo general, dos son los aspectos que deben considerar las opciones de financiamiento para la vivienda a fin de ser viables y sostenibles. Por un lado, deben ofrecer rentabilidad a los agentes que participan en el mercado, pues de otro modo no será factible atraer inversión, particularmente privada, hacia el sector habitacional. Por otro, deben ser adecuadas a la capacidad de pago de los potenciales prestatarios; en caso contrario, la población con menores ingresos quedará al margen de las operaciones del mercado.

Dado que ambos objetivos no son necesariamente compatibles, se ha producido en diversos contextos una gravitante intervención del Estado, que muchas veces se ha traducido en un enfoque paternalista y ha llevado a una mala asignación de los recursos - por el otorgamiento de créditos a tasas de interés subsidiadas- y a poca eficacia en la recuperación de los fondos prestados, con serios problemas de morosidad.

También se han ensayado otros esquemas que han procurado crear mayor espacio para la gestión privada en la construcción y el financiamiento de viviendas y han reservado al Estado, al menos en teoría, un rol fundamentalmente normativo y subsidiario de la capacidad de compra de los estratos de menores ingresos. Con tal propósito, la intervención del Estado se centra en el aporte de subsidios directos no reembolsables, con exigencia de ahorro previo a las familias beneficiarias. Dado que con frecuencia esto no basta para obtener el tipo de vivienda que las familias de menores ingresos pueden o desean adquirir, estas dos fuentes de financiamiento son complementadas con algún tipo de crédito para la vivienda.

Sin embargo, la provisión de crédito hipotecario en condiciones accesibles para las familias de menores ingresos no ha sido una tarea fácil. Por lo general, los esquemas institucionales de movilización de recursos para la vivienda no se han dotado de fondos de largo plazo, siendo que el financiamiento de la vivienda

$\square$ Este artículo es una versión abreviada de un estudio publicado con el mismo título por la CEPAL en la serie Financiamiento del desarrollo (CEPAL, 2002). Las opiniones vertidas en él son de exclusiva responsabilidad del autor. tiene precisamente un horizonte temporal de esa índole. La disponibilidad de fondos de corto plazo, básicamente ahorros familiares, no ha sentado bases de estabilidad para los sistemas financieros de vivienda y más bien ha creado riesgos potenciales - y muchas veces reales- de descalce de plazos y tasas. Además, el desarrollo relativamente limitado de los mercados de capital también ha incidido adversamente en la existencia de débiles vínculos entre éstos y el financiamiento de la vivienda.

Por otro lado, el bajo monto de las operaciones de crédito hipotecario para los sectores de menores ingresos y los elevados costos de transacción respecto de los montos involucrados han tendido, en un ambiente de competencia, a desalentar a los intermediarios financieros de otorgar créditos para vivienda a dichos sectores. En otras palabras, muchas de las opciones de crédito hipotecario disponibles en el mercado están, en la práctica, fundamentalmente dirigidas a los sectores con mayor capacidad adquisitiva.

El presente artículo formula un conjunto de consideraciones sobre el funcionamiento de opciones de crédito hipotecario disponibles en una muestra de ocho países latinoamericanos, ${ }^{1}$ así como recomendaciones de política que contribuyan a desarrollar los mercados de financiamiento habitacional y mejorar su impacto sobre el acceso a la vivienda, en especial para los sectores de menores ingresos.

\footnotetext{
${ }^{1}$ Los países considerados en el estudio son: Brasil, Chile, Colombia, Costa Rica, Ecuador, México, Perú y la República Dominicana. Además de la disponibilidad de información, otros criterios que han servido para conformar la muestra son: distribución geográfica (cinco países sudamericanos, uno centroamericano, uno norteamericano y uno caribeño); tamaño económico (dos países grandes: Brasil y México; tres medianos: Chile, Colombia y Perú; y tres pequeños: Costa Rica, Ecuador y República Dominicana), y aspectos institucionales que inciden en el sector vivienda (por ejemplo, un país, Ecuador, está legalmente dolarizado); otro, Perú, está dolarizado de facto; tres países (Chile, Colombia y México) tienen regímenes de indización vigentes; un país, Brasil, tiene antecedentes al respecto; y dos países (Costa Rica y la República Dominicana) carecen de tradición alguna de indización. El estudio también incluye el análisis de otros dos países - Argentina, país sudamericano de tamaño económico grande con un régimen monetario de convertibilidad hasta hace poco, y Panamá, país centroamericano de tamaño económico pequeño con régimen monetario de dolarización - en lo que concierne al desarrollo de los mercados secundarios de hipotecas.
} 
La sección II siguiente aborda aspectos conceptuales de la movilización de recursos para la vivienda, teniendo en cuenta diferentes modelos institucionales y operativos y considerando sus implicaciones para el funcionamiento y manejo de riesgos de los intermediarios, por un lado, y las interrelaciones de los mercados de vivienda y los mercados financieros y de capital, por el otro. Dado el doble objetivo de rentabilidad y accesibilidad que debiera tener todo instrumento de crédito para la vivienda, y el predominio en América Latina de vastos sectores de la población con bajo poder adquisitivo, se analiza desde el punto de vista teórico el aporte de los subsidios habitacionales a la demanda en la facilitación del acceso a la vivienda.
Por su parte, en la sección III se formula, sobre la base de los esquemas institucionales e instrumentos de crédito hipotecario existentes, un conjunto de conclusiones y recomendaciones de política conducentes a una gestión de financiamiento habitacional que permita alcanzar eficiencia y desarrollo sostenible en los mercados de créditos hipotecarios para la vivienda, y también que estos favorezcan efectivamente el acceso a la vivienda de los estratos de menores ingresos. Se atiende en especial al papel que le corresponde al Estado en el fomento de la formación de mercados hipotecarios, así como al acceso y el financiamiento de la vivienda para los sectores de menores ingresos.

\section{II}

\section{El crédito para vivienda: aspectos conceptuales}

\section{Modelos de movilización de recursos financie- ros para la vivienda}

La vivienda constituye un bien duradero; es quizá el más importante activo físico de la mayoría de las unidades familiares, y su precio suele ser varias veces superior a los ingresos de los potenciales demandantes. Por esta razón, la adquisición de vivienda, en los más de los casos, sólo resulta viable mediante un crédito de largo plazo, que permita diferir la presión que dicho precio ejerce sobre el ingreso familiar. Ahora bien, la disponibilidad de créditos de largo plazo para vivienda no sólo plantea interrogantes relativos a su volumen en relación con la demanda, sino también a la necesidad de transformación de plazos por parte de los originadores de tales créditos.

El modelo más tradicional de movilización de recursos financieros para la vivienda es aquel que se basa en la intermediación del sistema financiero (gráfico 1). En él participan bancos o entidades financieras de espectro múltiple - es decir, que financian diversas actividades, incluida la habitacional $-\mathrm{o}$, como sucedió antaño y sucede todavía en muchos países latinoamericanos, instituciones financieras especializadas en otorgar créditos hipotecarios para la vivienda. Como fuente primaria de fondos para este propósito, estas últimas captan los ahorros de las familias, prin- cipalmente mediante depósitos a plazos relativamente cortos.

Los créditos originados por estas instituciones permanecen como activos en sus balances durante todo el período de vigencia. Las instituciones prestamistas también se encargan de la administración y cobranza de dichos créditos. En otras palabras, desempeñan todas las funciones del proceso hipotecario: captación de recursos, y originación y administración de créditos. El hecho de que estas instituciones otorguen créditos de largo plazo con ahorros de corto plazo conlleva

\section{GRÁFICO 1 \\ Modelo tradicional de intermediación financiera para la vivienda}

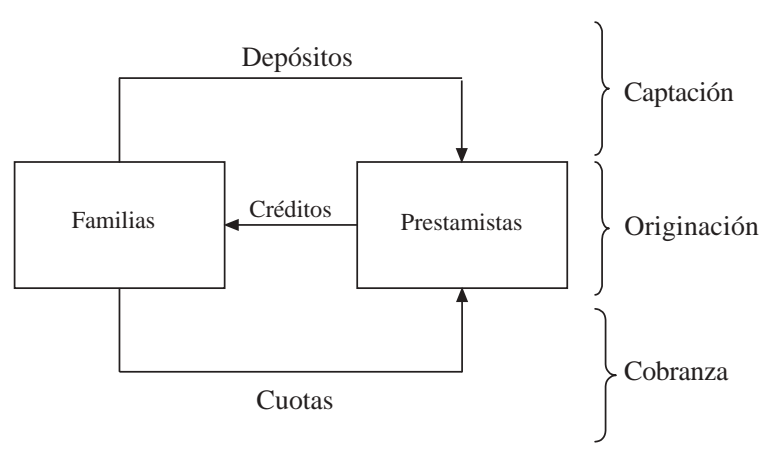

Fuente: Elaboración propia. 
riesgos potenciales de descalce de plazos, y posiblemente de tasas, cuando imperen topes a las tasas de interés para los créditos hipotecarios; estos riesgos se concentran en las instituciones prestamistas.

Con miras a atraer mayores recursos financieros hacia el sector vivienda, teniendo en cuenta que los mercados de capital cuentan con nuevos agentes inversionistas y más fondos de largo plazo, y a lograr que los plazos de dichos recursos calcen adecuadamente con los plazos de las colocaciones que financian, se viene prestando creciente atención a un modelo emergente de movilización de recursos. Éste se basa en el desarrollo de un mercado secundario de hipotecas, en el cual los créditos para vivienda son primero vendidos, por lo general a entes especializados en adquirir hipotecas de diferentes prestamistas, con cuyo respaldo se emiten títulos y valores que son adquiridos por inversionistas (generalmente institucionales) en los mercados de capital (gráfico 2).

Este proceso de cesión de hipotecas y su posterior securitización permite, en primer lugar, una rotación más rápida de los recursos que manejan las instituciones prestamistas, ya que dichos activos salen de sus balances antes de su vencimiento, a cambio de recursos para originar nuevos créditos y, en segundo lugar, establece un vínculo entre el financiamiento de la vivienda y los mercados de capital, lo que favorece la transformación de plazos que se precisa en el primer caso. En la versión más sofisticada de este modelo se produce una tendencia a la especialización de funciones dentro del proceso hipotecario: la institución prestamista pasa a ser fundamentalmente un ente que origina créditos, cuyos riesgos son trasladados y difundidos en el mercado de capital, diversificando sus fuentes de recursos e incluso traspasando la administración de los créditos a los entes especializados que puedan surgir.

Desde luego, la descripción anterior es muy simplificada y fundamentalmente sirve para señalar las diferencias entre un modelo de intermediación financiera para la vivienda y un modelo de movilización de recursos con el aporte de un mercado secundario de hipotecas. Existen, no sólo en el ámbito teórico, sino también en la práctica, algunas otras variantes. Un ejemplo son los fondos de vivienda — generalmente de carácter gubernamental - que proveen de recursos a las instituciones prestamistas; éstas, sobre la base de ciertas condiciones, otorgan créditos hipotecarios para vivienda que, dependiendo del grado de desarrollo de los mercados, pueden o no ser securitizados. Otro ejemplo es la obtención de recursos por parte de las instituciones prestamistas mediante la emisión de bonos u otros títulos hipotecarios, los que también sirven para establecer vínculos, aunque menos sofisticados, con los mercados de capital. ${ }^{2}$ De hecho, en América Latina, en diferentes momentos y en diversos países, se han dado éstas y otras variantes.

GRÁFICO 2

Movilización de recursos para la vivienda con un mercado secundario

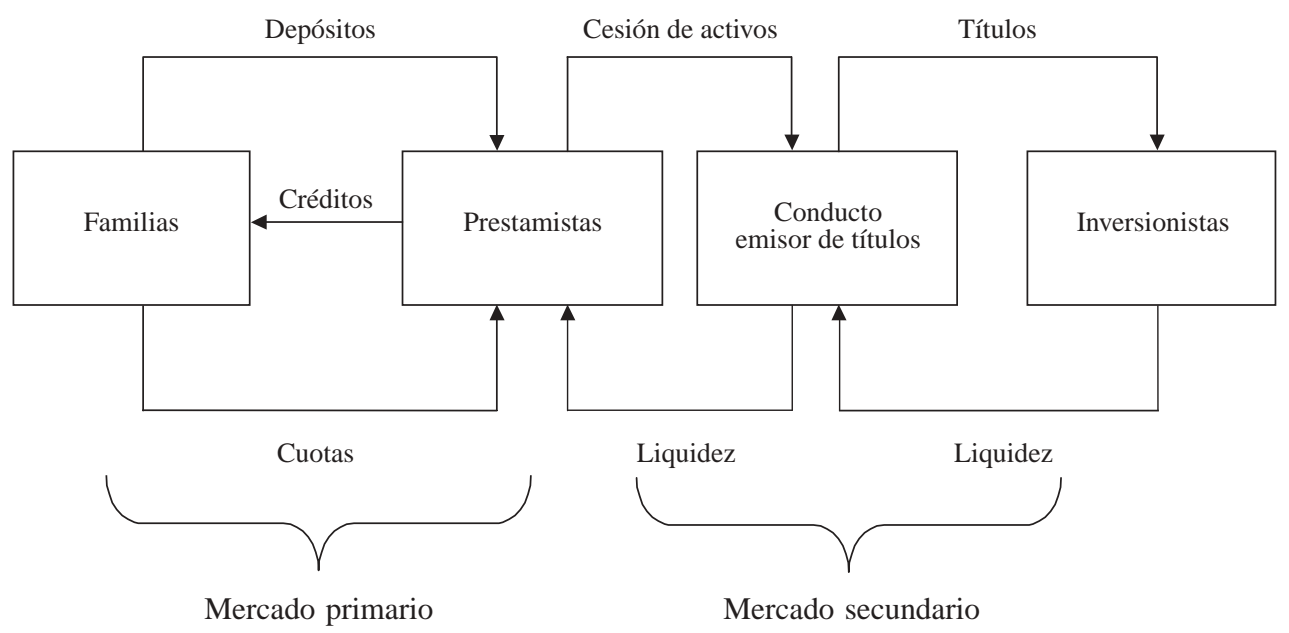

${ }^{2}$ Un caso destacable en la región es el maduro sistema de letras de crédito hipotecario en Chile; a su consolidación contribuyó la reforma previsional aplicada en el país a partir de 1981, que ha ve-

nido generando crecientes ahorros internos de largo plazo, así como la aparición de las compañías de seguros de vida como otro importante inversionista institucional adquiriente de dichas letras. 
Lo cierto es que existe una clara tendencia a reevaluar los esquemas institucionales para la movilización de recursos hacia el sector habitacional. Lo que se busca es asegurar un mayor volumen de créditos hipotecarios habitacionales y a la vez procurar que los recursos se obtengan en condiciones de plazo compatibles con el financiamiento de viviendas. Así, se advierte un desplazamiento del modelo tradicional, circunscrito al mercado financiero, de movilización de ahorros familiares de corto plazo para otorgar créditos habitacionales de largo plazo. Pero tal desplazamiento no apunta a descartar este modelo tradicional, que continuará siendo importante en la gran mayoría de los países en desarrollo, sino a complementarlo con un esquema que obtenga recursos tanto del mercado financiero como del mercado de capital, a través de mecanismos tradicionales de captación de ahorros familiares y de mecanismos de captación de ahorros institucionales, para originar créditos hipotecarios que puedan ser securitizados.

A partir de la separación de las funciones de originación de créditos hipotecarios y de captación de ahorros del público, se vislumbra una tendencia hacia la captación del ahorro general de la economía - ya sea el que se deposita en los bancos múltiples o en las instituciones financieras especializadas, el que administran inversionistas institucionales o, incluso, el ahorro del resto del mundo- para canalizarlo de alguna forma al financiamiento de la vivienda, a través de innovaciones en los instrumentos de movilización de recursos. ${ }^{3}$ Esto probablemente ocurra en desmedro de la captación de ahorros forzosos específicamente dedicados a financiar vivienda, entre otros motivos por las limitaciones que impone al volumen de recursos que son movilizables por esta vía. El esquema emergente antes descrito debe contribuir a resolver el problema de descalce de plazos y la necesidad de diseminar los riesgos. ${ }^{4}$

\section{Vinculación del crédito para vivienda con los subsidios habitacionales directos y el ahorro previo}

Las instituciones que financian vivienda deberán competir por recursos en el mercado financiero y de capi-

\footnotetext{
${ }^{3}$ Véase Hausmann (1998, p. 11).

${ }^{4}$ Esta tendencia se verifica en el contenido de algunas reformas que recientemente se vienen introduciendo en los marcos legales e institucionales para el financiamiento de la vivienda en varios países de la región.
}

tal. Para ello tendrán que contar con instrumentos que ofrezcan rentabilidades atractivas, tanto a los ahorradores como a los inversionistas; por lo tanto, deberán diseñar instrumentos de crédito hipotecario en condiciones de mercado. Esto quiere decir que las amortizaciones de los créditos para vivienda deben permitir la recuperación de los préstamos en valores reales, para posibilitar el financiamiento de una nueva vivienda asî como su venta en el mercado secundario. Se argumenta que subsidiar a una familia significa gravar a 20 ahorradores que recibirán rentabilidades bajas o incluso negativas por sus depósitos, lo cual desincentiva el ahorro y obstaculiza el crecimiento del sistema financiero. ${ }^{5}$

Sin embargo, este objetivo no es necesariamente compatible con las posibilidades de acceso a las opciones de crédito hipotecario que tienen los potenciales prestatarios, principalmente los de sectores con menores ingresos. El obstáculo principal para solucionar el déficit habitacional que aqueja a estos sectores ha sido precisamente su dificultad de acceder a las oportunidades de financiamiento existentes, por tres razones básicas: i) su insuficiente capacidad adquisitiva, que les impide transformar su enorme demanda potencial en una demanda efectiva; ii) su carencia de garantías satisfactorias para obtener los créditos hipotecarios disponibles, y iii) sobre todo en países con sectores informales importantes, su imposibilidad de acreditar ingresos permanentes. Es clara entonces la insuficiencia del binomio ahorro previo/crédito hipotecario para concretar el acceso a vivienda de los sectores de menores ingresos, aunque esto sí puede ser factible en los estratos de ingresos más elevados.

Para este problema han surgido esquemas tripartitos encaminados a facilitar el acceso a la vivienda. Sus componentes son: el ahorro previo de los adquirientes, un subsidio a la demanda de carácter no reembolsable otorgado por el Estado y, si es del caso, un crédito hipotecario complementario en condiciones de mercado. El objetivo central del subsidio habitacional directo (SHD) es complementar la capacidad adquisitiva de las familias de menores ingresos, segmento donde se concentra el grueso de la demanda potencial de vivienda, para permitir que estas familias puedan resolver su problema habitacional a través del mercado, accediendo a una vivienda que satisfaga sus aspiraciones y que sea compatible con su esfuerzo propio y sus posibilidades económicas. Se considera que los subsidios a la demanda son claramente más eficientes que los subsidios a la

\footnotetext{
${ }^{5}$ Véase Renaud (1997, p. 13).
} 
oferta (en la forma de viviendas provistas por el Estado), debido a que significan menores pérdidas en el bienestar del consumidor, menores pérdidas en la soberanía del consumidor y menores costos en la facilitación de una vivienda. ${ }^{6}$

El impacto de los subsidios habitacionales directos sobre las posibilidades adquisitivas de los beneficiarios se ilustra en el gráfico $3 .^{7}$ Para simplificar el análisis, supóngase que la canasta de consumo de la familia en cuestión está compuesta por dos bienes: la vivienda y el resto de los bienes. ${ }^{8}$ Dado su nivel de ingreso (mensual), dicha familia tiene un conjunto factible de consumo representado por el área АОВ y, en función de sus preferencias, elige, por ejemplo, la canasta C (consume OD de vivienda y OE de otros bienes). Supóngase que esta familia resulta beneficiaria de un subsidio habitacional, con lo cual su conjunto factible de consumo se amplía y ahora es representado por el área AOFG. Se produce entonces un incremento del ingreso real de esta familia que desplaza la línea de presupuesto, denotada ahora por la recta FG; esta recta se trunca en el punto G, dado que el subsidio sólo puede utilizarse para consumir vivienda (el subsidio no es entregado en dinero y, por lo tanto, no es fungible).

El gráfico 3 bien puede representar el caso de una familia beneficiaria de un subsidio habitacional directo obtenido en el programa de leasing habitacional (arrendamiento con promesa de compraventa), tal como funciona en Chile. Como se trata de un subsidio que es aportado por el Estado de manera parcial y metódica en el tiempo, lo más probable es que la elección de la nueva canasta de consumo se ubique en el tramo HI, pudiendo servir el subsidio para agregarlo al presupuesto y obtener una vivienda mejor y de mayor valor (punto $\mathrm{H}$ ), o para liberar parte del presupuesto que utiliza la familia beneficiaria para pagar arriendo, por el equivalente del subsidio, y dedicarlo a consumir más de los otros bienes (punto I), o bien para una combinación de ambas cosas (tramo HI).

Los subsidios habitacionales directos tienen diversas ventajas, pero aquí destacaremos tres que guardan directa relación con el desarrollo mismo del mercado de créditos hipotecarios. ${ }^{9}$ En primer lugar, dichos sub-

\footnotetext{
6 Véase Renaud (1997, pp. 3-4).

7 Véase en Gonzales Arrieta (1999) una explicación detallada sobre la racionalidad económica de los subsidios habitacionales directos.

${ }^{8}$ Según el Teorema del Bien Compuesto de Hicks, si un grupo de bienes mantiene sus precios relativos constantes, puede considerarse como un solo bien.

${ }^{9}$ Los subsidios habitacionales directos tienen otras importantes ventajas, particularmente en términos de equidad — permiten una
}

\section{GRÁFICO 3 \\ Impacto de un subsidio habitacional directo sobre el ingreso real}

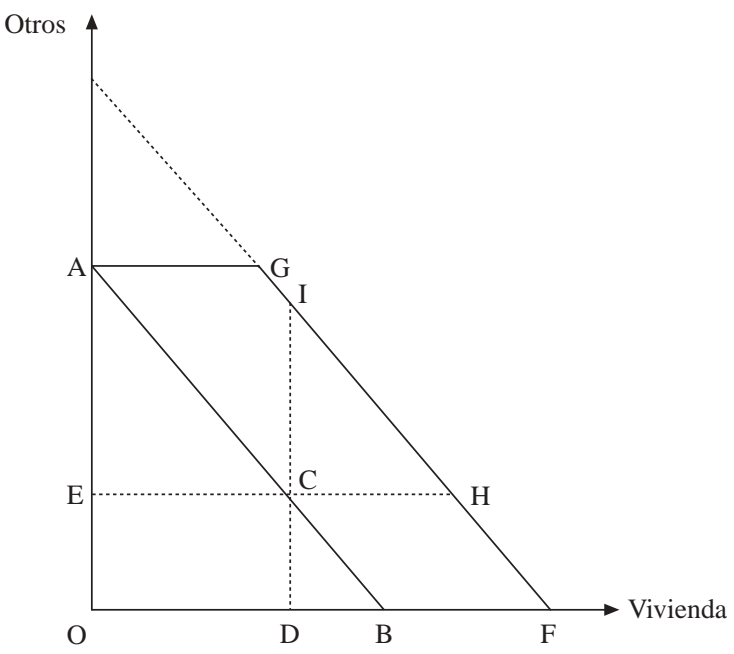

sidios contribuyen a ampliar el mercado potencial de prestatarios hipotecarios, al reducir el monto de endeudamiento necesario para completar el precio de la vivienda que se adquirirá. Por lo tanto, permiten a las familias beneficiarias convertirse, con sus mismos ingresos monetarios, en sujetos de créditos hipotecarios por montos compatibles con su capacidad de pago permanente. Asimismo, el menor endeudamiento a que dan lugar tales subsidios puede estimular al sistema financiero formal a aumentar el volumen de créditos habitacionales para los sectores de menores ingresos, y también a ofrecer una cartera de mejor calidad, pues además de que el deudor asume una obligación más fácil de pagar, dado su nivel de ingresos, la cobertura de la garantía hipotecaria arroja un excedente sobre la deuda (equivalente al monto del subsidio).

En segundo término, los subsidios habitacionales directos, como parte de los esquemas tripartitos para facilitar el acceso a la vivienda antes descritos, pueden estimular la formación de ahorros financieros canalizados a través del sistema financiero formal, si están orientados a premiar el monto, la antigüedad, la permanencia y el carácter metódico del ahorro previo. Esto es así cuando se establece el ahorro previo metódico como requisito para la adjudicación de tales subsidios. A su vez, la formación de ahorros previos a través del

mejor focalización y progresividad — y en términos de estimular el esfuerzo y la capacidad de los beneficiarios para escoger su solución habitacional. Véase Gonzales Arrieta (1999, pp. 142-143). 
sistema financiero puede contribuir a ampliar la base de potenciales prestatarios, incorporando a grupos que tradicionalmente son rechazados por su incapacidad de acreditar ingresos permanentes.

En tercer lugar, los subsidios habitacionales directos, a diferencia de los subsidios a las tasas de interés, acentúan y no distorsionan la operación del mercado financiero de vivienda. Complementan, y no desplazan, el crédito hipotecario en condiciones de mercado: la contrapartida del subsidio habitacional directo en los segmentos con cierta capacidad de endeudamiento debe ser una operación de crédito hipotecario en tales condiciones. Por lo tanto, la vigencia del mecanismo de subsidio de esta índole es perfectamente compatible con un esquema de movilización de recursos financieros para la vivienda con tasas de interés reales positivas, tanto para los ahorros como para los créditos, que estimule la afluencia de recursos financieros hacia el sector y también la capitalización de los intermediarios financieros.

\section{III}

\section{Fortalecimiento de los instrumentos de crédito hipotecario para la vivienda: recomendaciones de política}

\section{Panorama general en América Latina}

La vigencia y la eficacia de los instrumentos de crédito hipotecario para la vivienda se sustenta sobre dos bases fundamentales: por un lado, la posibilidad de movilizar recursos de largo plazo para ser destinados al financiamiento de la vivienda y, por otro, la posibilidad de diseñar productos de crédito hipotecario que contribuyan al acceso a la vivienda de las familias con capacidad de endeudamiento.

Claramente, la movilización de recursos de largo plazo por los sistemas financieros de vivienda es una tarea pendiente en la mayoría de los países de América Latina. Países como Brasil, con su antiguo Sistema de Financiamiento Habitacional (SFH); Colombia, con el extinto sistema basado en la unidad de poder adquisitivo constante (UPAC); Costa Rica, con el Sistema Financiero Nacional para la Vivienda (SFNV), y la República Dominicana, con el Sistema Dominicano de Ahorros y Préstamos para la Vivienda, por citar solamente algunos, sustentan primordialmente la actividad de créditos para vivienda de largo plazo con recursos captados en los mercados financieros, muchos de ellos de corto plazo. En efecto, el SFH de Brasil emplea las denominadas cadernetas de poupança, un instrumento de captación de ahorros a la vista cuyo crecimiento real, desde 1981 en adelante, tendió a ser inferior al de los activos financieros no monetarios; además, estos depósitos han sido muy volátiles y prevalece un rígido esquema de colocación de los recursos captados por esta vía. En Costa Rica, una de las principales debilidades de las mutuales, que forman parte del SFNV, es el descalce de plazos entre sus captaciones - principalmente ahorros del público a corto plazo - y sus colocaciones de largo plazo. Este tradicional esquema para financiar créditos de largo plazo con ahorros de corto plazo es potencialmente vulnerable, por los riesgos de descalce de plazos y tasas que conlleva.

Otros países se amparan en los ahorros forzosos - por ejemplo, el Fondo de Garantía por Tiempo de Servicios (FGTS) en Brasil o los descuentos por nómina en el Instituto del Fondo Nacional de Vivienda para los Trabajadores (INFONAVIT) y otros fondos en México-; o en la constitución de fondos de origen estatal que son intermediados por el sistema financiero, como el Banco Ecuatoriano de la Vivienda (BEv), el extinto Fondo de Operación y Financiamiento Bancario a la Vivienda (FOVI) en México, cuyas funciones hoy realiza la Sociedad Hipotecaria Federal (SHF), ${ }^{10}$ o el Fondo Mivivienda en Perú. Además de las restricciones que pueden imponer estos mecanismos en cuanto al monto de los recursos disponibles, el hecho de depender de este tipo de recursos dificulta en muchos casos que las instituciones prestamistas puedan autosustentarse.

\footnotetext{
${ }^{10}$ Cabe señalar que la facultad de la SHF de otorgar préstamos no puede extenderse más allá del 12 de octubre del 2009.
} 
En Brasil, dado que los depósitos del FGTs dependen mucho de variables tales como el nivel de empleo, el poder adquisitivo de las remuneraciones y la participación del empleo formal, en épocas de adverso desempeño macroeconómico se ha verificado una acentuada descapitalización del FGTs, atentando también contra la estabilidad del crédito inmobiliario. En Perú, es claro que el aporte inicial del Fondo Mivivienda, incluyendo sus recuperaciones y su rentabilidad, no será suficiente para atender de manera sostenida las necesidades de financiamiento habitacional. ${ }^{11}$

Dado que el financiamiento y el acceso a la vivienda sólo es posible con un crédito de largo plazo para las familias con capacidad de endeudamiento, la ingeniería financiera del crédito hipotecario habitacional demanda la transformación de plazos. Para ello, es menester crear vínculos entre el mercado de financiamiento para la vivienda y el mercado de capital, el cual ofrece, en principio, a los sistemas financieros de vivienda la posibilidad de disponer de recursos en volúmenes y plazos que la sola intermediación en el mercado financiero no puede aportar. El desarrollo de un mercado secundario de hipotecas es el vehículo para establecer este vínculo entre el sistema financiero de vivienda y el mercado de capitales.

En América Latina se están llevando a cabo iniciativas legales, institucionales y operativas que apuntan a encaminar los sistemas financieros de vivienda hacia una vinculación con el mercado de capital para atraer recursos de largo plazo destinados al financiamiento de la vivienda. Existiendo recursos (ahorros) de largo plazo e inversionistas institucionales, como viene siendo el caso en muchos países en mayor o menor medida, una forma de lograr lo anterior es mediante la securitización de hipotecas. Sólo por citar algunos ejemplos, en Brasil la creación del Sistema Financiero Inmobiliario (SFI) incorpora claramente esta idea; en Colombia la nueva legislación que norma el desarrollo sectorial contempla instrumentos para establecer tales vínculos; en México algunas reformas legales y la creación de la Sociedad Hipotecaria Federal buscan crear condiciones propicias para la securitización, y en Ecuador y Perú existe ya un marco legal y bases institucionales para permitirla.

Las posibilidades de desarrollar los mercados secundarios de hipotecas se sostienen en la imperiosa

\footnotetext{
${ }^{11}$ En alineación con esta realidad, el Fondo Mivivienda viene trabajando en el diseño de productos de garantía y de otra índole que permitan estimular la movilización de recursos para financiamiento de otras fuentes, entre ellas, del mercado de capital.
}

necesidad de contar con sólidos mercados primarios que sean la base para el diseño de productos con los cuales se pueda concurrir al mercado de capital y que éste, a su vez, cuente con recursos de largo plazo. Sin embargo, la experiencia en esta materia señala que este proceso es incipiente - hoy día apenas seis países de la región (Argentina, Brasil, Chile, Colombia, México y Panamá) registran emisiones de bonos securitizados con respaldo de hipotecas-, en parte por las debilidades de los propios mercados primarios de hipotecas pero también por una serie de dificultades, particularmente las recientes crisis financieras que han deteriorado las carteras de crédito hipotecario y han generado incertidumbre para inversiones financieras de largo plazo. Ahora bien, la securitización de hipotecas no es la única vía para establecer vínculos entre el financiamiento de la vivienda y el mercado de capital. Desde hace muchos años Chile ha sido capaz de establecer esos vínculos mediante el uso de las letras de crédito hipotecario, un instrumento que domina el mercado hipotecario chileno y que es sumamente líquido, además de permitir calzar absolutamente los activos y los pasivos de las instituciones emisoras. En este país, la securitización está sirviendo para crear vínculos adicionales con el mercado de capital, permitiendo sobre todo mitigar los riesgos de otros instrumentos, como los mutuos hipotecarios endosables y los contratos de leasing habitacional.

Como se ha señalado, lo anterior permite vislumbrar una tendencia a movilizar el ahorro general de la economía para el financiamiento habitacional, es decir, no sólo el ahorro del público en las instituciones del sistema financiero, sino también el ahorro de inversionistas institucionales que participan en los mercados de capital. Ahora bien, para poder continuar concurriendo al mercado financiero y poder concurrir al mercado de capital, el sistema financiero de vivienda tiene que hacerlo con instrumentos (como depósitos, hipotecas, bonos) aislados de los subsidios. La necesidad de que los sistemas financieros de vivienda otorguen créditos hipotecarios en condiciones de mercado, sin subsidios, está estrechamente relacionada con las posibilidades que tendrán dichos sistemas de establecer vínculos con los mercados de capital, a fin de ampliar su captación de recursos y mejorar el manejo de sus riesgos. Asimismo, para afianzar la capacidad de cualquier sistema financiero habitacional de estimular la captación de ahorros familiares a través del sistema financiero, es indispensable que dichos ahorros tengan una rentabilidad positiva en términos reales, que no sólo impida su depreciación en el transcurso del 
tiempo, sino que la conviertan en una alternativa preferible a otras opciones. Una condición como ésta sería incompatible con que las propias instituciones receptoras de los ahorros familiares otorguen créditos con algún contenido de subsidio, si de lo que se trata es de asegurar que los instrumentos de financiamiento para la vivienda sean autosostenibles en el largo plazo.

De todo lo anterior se desprende que, además de dotar de recursos de largo plazo al mercado primario de hipotecas, es menester que prevalezca el criterio de rentabilidad para asegurar la aparición y permanencia del crédito hipotecario. Los esquemas de amortización deben estar concebidos de manera que aseguren la recuperación de los créditos en valores reales. Esto es importante no sólo para descartar subsidios ocultos, sino también para evitar la descapitalización de los intermediarios y permitir que la recuperación de cartera llegue a constituir la principal fuente de recursos de los sistemas financieros de vivienda. En este sentido, en América Latina se han ensayado diversos modelos de indización, particularmente para contrarrestar los efectos adversos de la inflación. Para citar algunos ejemplos, Chile, Colombia y México utilizan un esquema de indización de los créditos que toma como referencia la inflación, mientras que en Ecuador y Perú las hipotecas están total o mayoritariamente dolarizadas. En cambio, Costa Rica y la República Dominicana otorgan créditos para vivienda en moneda local a tasas de interés variables.

Si bien es cierto que actualmente la inflación no es un problema económico relevante en la región, cualquier instrumento de financiación de largo plazo, como es el crédito para vivienda, tendrá mejores posibilidades de desarrollarse si está asociado a un esquema de indización que lo proteja de los riesgos de inflación y devaluación; es decir, que desempeñe un papel de "seguro". Más aún, países con mucha tradición en el uso de este esquema — como Chile- no consideran ni remotamente la posibilidad de prescindir de la indización, a pesar de la trayectoria sostenida de estabilidad de precios alcanzada. Desde luego, ningún sistema de indización es garantía cuando se entra en una espiral inflacionaria o devaluatoria descontrolada; de hecho, muchos de ellos han fracasado en esas circunstancias. En el tema de la indización, queda también como tarea pendiente la forma de cautelar o compensar posibles incapacidades de pago por parte de los deudores cuando los salarios no siguen el ritmo de la inflación (si éste es el factor de indización) o de la devaluación (si los créditos están dolarizados).

Las condiciones anteriores encaminadas a asegurar la rentabilidad y la autosostenibilidad de los siste- mas financieros de vivienda debieran dar lugar a que el acceso a la vivienda pueda alcanzarse mediante una combinación del ahorro previo y crédito hipotecario de largo plazo. Sin embargo, esto no asegura que todos los segmentos de la población, particularmente los de menores ingresos, puedan tener pleno acceso a las oportunidades que genera el funcionamiento de un sistema financiero de vivienda en tales condiciones. Por lo tanto, en sociedades en desarrollo con ingresos relativamente bajos y vastos sectores de población de escaso poder adquisitivo, como las prevalecientes en América Latina, ${ }^{12}$ para desarrollar sólidos sistemas financieros de vivienda es indispensable establecer una clara separación entre subsidio y financiamiento. Cuando se ha intentado aplicar algún mecanismo de financiamiento para la vivienda que contenga algún subsidio (por ejemplo, a la tasa de interés de los créditos) con el propósito de facilitar el acceso a la vivienda de los sectores de menores ingresos, usualmente a la larga no se han obtenido los resultados esperados $\mathrm{y}$, antes bien, se ha atentado contra la autosostenibilidad del sistema financiero de vivienda.

Ciertamente, aquí hay otra tarea pendiente: cómo armonizar los criterios de rentabilidad que favorecen el desarrollo de un sistema financiero de vivienda autosostenible con el criterio de acceso y de protección de la capacidad de pago de los deudores hipotecarios. Los instrumentos de crédito hipotecario habitacional disponibles en los mercados financieros de vivienda de varios países son usualmente accesibles para los estratos de ingresos relativamente más altos y difícilmente contribuyen a facilitar el acceso a la vivienda de los segmentos con limitada capacidad de endeudamiento. Las colocaciones del SFH en Brasil, cuando se utilizan los recursos de las libretas de ahorro, están destinadas a familias de ingresos medios altos (superiores a 1.000 dólares mensuales). En Chile los mutuos hipotecarios endosables se utilizan activamente para el financiamiento de viviendas de mayor valor: el valor medio de las colocaciones acumuladas con este instrumento a cargo de las administradoras de mutuos hipotecarios endosables asciende a 37.000 dólares. La población atendida mediante el Programa Financiero de Vivienda

\footnotetext{
12 En CEPAL (2001) se señala que en los países de América Latina y el Caribe el $10 \%$ de hogares con más recursos percibe una proporción del ingreso total 19 veces mayor, en promedio, que la que recibe el $40 \%$ de hogares más pobres. Más aún, entre dos tercios y tres cuartos de la población, dependiendo del país, perciben un ingreso por habitante inferior al promedio general. Así, en el decenio de 1990 la región mantuvo la distribución del ingreso más desigual del mundo.
} 
(PROFIVI) en México, antes administrado por el Fovi y hoy por la SHF, se concentra en un $37 \%$ del total de créditos en los rangos de ingresos mensuales de $780 \mathrm{a}$ 1.300 dólares, y en un 35\% en los de 1.300 a 1.950 dólares. El monto promedio de los créditos del Fondo Mivivienda en Perú es de alrededor de 18.000 dólares, lo que significa que estos recursos están llegando fundamentalmente a familias con ingresos mensuales entre 530 y 585 dólares.

De hecho, en la política pública de América Latina hay una corriente de reconocimiento casi generalizada de que el binomio ahorro y crédito (en condiciones de mercado) es insuficiente para atender las necesidades de vivienda de grandes sectores de la población, teniendo en cuenta que casi todos los países de la región disponen desde hace cierto tiempo de algún régimen de subsidios habitacionales directos que constituye un eje central de la política pública para atender al déficit habitacional de los sectores de menores ingresos.

\section{El papel del Estado en la creación de un mer- cado hipotecario}

De cara a esta tarea pendiente, la participación del Estado resulta decisiva. Ahora bien, durante muchos años el Estado ha tenido activa participación en el sector vivienda, procurando atender a los sectores de menores ingresos; sin embargo, muchas veces esta participación estatal ha desplazado la incursión del sector privado y, finalmente, no ha logrado atender a la población que es su objetivo. Más recientemente, en América Latina se observa una tendencia al retiro del Estado de la construcción y el financiamiento directo de vivienda, preconizándose, en su lugar, un papel fundamentalmente normativo y promotor de la iniciativa privada. Algunas experiencias, como las de Chile, Costa Rica, Ecuador y México, entre otras, dan cuenta de este cambio de orientación y de que se hallan en el camino correcto. Pero esas mismas experiencias permiten identificar también algunas insuficiencias: por ejemplo, en esquemas de esa naturaleza no siempre se ha podido atraer la participación del sector privado en el otorgamiento de créditos hipotecarios de bajo monto. Por lo tanto, debe precisarse que en sociedades de bajos ingresos con amplios sectores de población de escasa capacidad adquisitiva, se necesita una participación del Estado que trascienda el papel normativo a fin de asegurar a esos sectores un mayor acceso a la vivienda. Para que esa participación no incurra en el vicio de desplazar a la iniciativa privada y sí refuerce la autosostenibilidad de los sistemas fi- nancieros de vivienda, es necesario considerar diversos instrumentos.

En general, en el caso de los sectores de menores ingresos, las posibilidades de acceso a la vivienda deben basarse en la combinación de hasta tres elementos: i) el ahorro previo de los adquirientes (o alguna expresión del esfuerzo propio, no necesariamente de carácter monetario, para el caso de los estratos de mínimos ingresos); ii) un subsidio estatal directo, no reembolsable, en apoyo a la demanda de vivienda, y iii) con carácter complementario para los estratos con cierta capacidad de endeudamiento, un crédito hipotecario de largo plazo en condiciones de mercado. Evidentemente, así como para las familias con suficiente capacidad adquisitiva debiera bastar el binomio ahorro y crédito para acceder a una vivienda, en los sectores más pobres, con nula capacidad de endeudamiento, el acceso a la vivienda debe apoyarse fundamentalmente en la ayuda estatal en forma de subsidio directo (por ejemplo, una vivienda básica o progresiva), quizá añadiéndole algún componente de ahorro o esfuerzo familiar.

En esta perspectiva, el mecanismo del subsidio habitacional directo debe ser utilizado como palanca para transformar la demanda potencial de vivienda en demanda efectiva, sin introducir distorsiones en el funcionamiento del mercado financiero habitacional; para lograrlo habrá que separar la porción del mercado de vivienda que carece de suficiente capacidad adquisitiva y necesita una contribución estatal, de aquella porción con capacidad de pago que puede ser atendida con mecanismos de mercado por los intermediarios privados. Más aún, como ya se destacó, el subsidio habitacional directo puede contribuir al crecimiento del mercado potencial de prestatarios hipotecarios, al reducir el monto de endeudamiento necesario para completar el precio de la vivienda; la excepción es el caso de la población más pobre, a la cual sólo puede darse una solución habitacional combinando ahorro previo y un subsidio estatal. Al pasar revista a la experiencia de la región, se observa claramente que este mecanismo forma parte integral de las políticas de vivienda en un número cada vez mayor de países.

Desde luego, el otorgamiento del subsidio habitacional directo no ha bastado para garantizar que las instituciones financieras privadas den crédito hipotecario complementario a la población beneficiaria o, más en general, a los estratos de menores ingresos. Más aún, la falta de crédito hipotecario que complemente el subsidio estatal ha restado eficacia a este último instrumento, pues eleva la proporción de subsidios adjudicados que no se cobran. En este sentido, la experiencia 
latinoamericana también arroja luces sobre otras vías de intervención estatal que resultan prometedoras si lo que se pretende es no distorsionar el funcionamiento del mercado financiero de vivienda. Una de ellas es, por ejemplo, el esquema de créditos hipotecarios con intereses preferenciales que emplea la banca hipotecaria en Panamá.

Este mecanismo está orientado a que los prestamistas hipotecarios originen hipotecas a tasas de interés de mercado, pero que califiquen a posibles prestatarios a tasas de interés preferenciales (es decir, por debajo de las tasas de mercado), a fin de ampliar el acceso a un mayor número de familias. Para cubrir la diferencia de tasas que se genera, el gobierno otorga a los prestamistas hipotecarios títulos tributarios transables en un mercado secundario para éstos. Las hipotecas son originadas teniendo como base la tasa de referencia que calcula y publica la Comisión Bancaria Nacional en función de la tasa media de los créditos hipotecarios de los cinco bancos con las carteras hipotecarias más grandes del sistema. El mecanismo se aplica a créditos para adquirir viviendas de hasta 62.500 dólares, contemplándose dos tramos: el primero es el de viviendas de hasta 25.000 dólares, para cuyos créditos el gobierno le reconoce al prestamista un reembolso (en títulos tributarios) de cinco puntos porcentuales; el segundo tramo abarca viviendas cuyo valor supera los 25.000 dólares pero no excede los 62.500 , y en este caso el gobierno reconoce un reembolso de cuatro puntos porcentuales. El intermediario financiero solicita al gobierno el reembolso al final del año, en función del valor de las hipotecas otorgadas. El prestatario paga efectivamente una tasa preferencial definida como la diferencia entre la tasa de referencia (de mercado) y la tasa que habrá de reintegrar el gobierno (4 ó 5\%, según el caso). La cuota del préstamo puede ser deducida del sueldo del prestatario por la empresa empleadora, la que remitirá los pagos a las instituciones prestamistas; con esto se procura mejorar los niveles de cobranza, especialmente tratándose de préstamos de montos relativamente bajos.

Nótese que en este caso no se trata de un subsidio que recibe el deudor hipotecario a costa de la descapitalización de la institución financiera, como ha sido y es práctica usual en muchos países. En realidad dicha institución entrega los créditos hipotecarios a tasas de mercado, pues el Estado cubre la diferencia de tasas con títulos tributarios negociables. Si bien el esquema es menos progresivo que el subsidio habitacional directo - ya que a mayor crédito, mayor es el monto del subsidio-, ha probado su eficacia no sólo para dinamizar la actividad de crédito hipotecario en Panamá, sino también para permitir la generación de una masa de hipotecas que es perfectamente securitizable y atractiva para el mercado de capital. En otras palabras, se ha creado en el mercado primario de hipotecas un producto que ha permitido establecer vínculos con el mercado de capital a fin de canalizar recursos de largo plazo hacia el financiamiento de la vivienda. De hecho, en Panamá una altísima proporción del activo subyacente en las emisiones de bonos securitizados con respaldo de hipotecas está constituida por créditos originados en el ámbito de la Ley de intereses preferenciales.

Otra forma de intervención estatal es la asignación de subsidios estatales a las instituciones financieras para cubrir los costos fijos en que deben incurrir por otorgar y administrar créditos hipotecarios de bajo monto, en los cuales los costos fijos son proporcionalmente más elevados. Si bien en el plano teórico debiera fomentar una mayor disponibilidad de créditos hipotecarios de bajo monto para familias con cierta capacidad de endeudamiento, este mecanismo sólo se ha aplicado en Chile y desde hace poco tiempo. Es una de las innovaciones de la renovada política habitacional chilena, que se aplica desde comienzos del 2002, con miras a estimular una mayor participación de los prestamistas privados en créditos hipotecarios que complementen los subsidios habitacionales directos y también a retirar al Estado de la tarea de otorgar y administrar créditos de bajo monto, en la cual, por lo demás, registra antecedentes poco favorables. Las familias chilenas de menores ingresos han tenido un limitado acceso a las opciones de crédito para vivienda ofrecidas en el mercado. ${ }^{13}$ En tal situación, el Estado ha actuado en la práctica como un activo prestamista hipotecario para los segmentos de menores ingresos que calificaban para el Programa de Vivienda Básica del Ministerio de Vivienda y Urbanismo (MINVU). Autores como Pardo (1998) y Rojas (1999) encontraron que el desempeño estatal en este sentido era considerado altamente insatisfactorio. Se estima que aun después de muchas renegociaciones, más del $60 \%$ de la cartera hipotecaria del MINVU se encuentra con más de tres cuotas impagas, y la morosidad explica prácticamente tres cuartas partes de los subsidios ocultos. ${ }^{14}$

\footnotetext{
13 Véase Rojas y Greene (1995, pp. 31-49).

${ }^{14}$ Véase Almarza (2000, pp. 237-257). Cabe señalar que en Chile, a partir del 2002, se ha aplicado una política de "premios" para disminuir la morosidad de los créditos del minvu, y se ha logrado reducirla considerablemente.
} 
Complementariamente, la experiencia latinoamericana muestra que las garantías estatales para cubrir parcialmente el riesgo crediticio que conllevan los créditos hipotecarios para la vivienda pueden servir para estimular la participación de instituciones financieras privadas. Generalmente este tipo de garantías está vinculado con fondos de vivienda estatales. En México la SHF otorga a los intermediarios financieros una garantía por incumplimiento del deudor: si éste deja de pagar, la SHF cubre la primera pérdida hasta por el $25 \%$ del saldo insoluto del crédito, para lo cual se cobra una prima. Por su parte, los intermediarios financieros que operan con el Fondo Mivivienda en Perú cuentan con una cobertura de riesgo crediticio de un tercio del crédito, además de ser una cobertura subordinada (es decir, primero el banco cobra sus dos tercios y luego el Fondo Mivivienda recupera el tercio restante). En este sentido, se debieran explorar, como de hecho ya lo están haciendo algunos países, las posibilidades de establecer más ampliamente en la región la figura del seguro de hipotecas, para proteger a los prestamistas de posibles pérdidas por incumplimiento en el pago de las hipotecas, por un lado, y posibilitar que los prestatarios accedan a créditos hipotecarios con una menor cuota inicial, por el otro.

La conveniencia de manejar hipotecas indizadas respecto de la inflación o, como en algunos países, dolarizadas, dado el intrínseco horizonte de largo plazo del crédito hipotecario, conlleva el requerimiento de asegurar una adecuada protección de la capacidad de pago del deudor durante la vigencia del crédito. En este sentido, también será importante contar con iniciativas del Estado para establecer algún mecanismo que permita compensar cualquier incapacidad de pago de los deudores derivada del rezago de las remuneraciones respecto de la inflación, cuando éste es el factor de indización, o de la devaluación, cuando los créditos están dolarizados.

En México, desde 1999 se emplea una hipoteca con una garantía de riesgo sistémico que cubre posibles caídas extraordinarias o permanentes del salario mínimo en términos reales, para permitir que los prestatarios paguen en términos de salarios mínimos una hipoteca denominada en unidades de inversión (UDI). ${ }^{15}$ $\mathrm{El}$ instrumento que se utiliza para que los pagos de los deudores sólo se incrementen con referencia al salario mínimo, a pesar de que el crédito está denominado en

\footnotetext{
${ }^{15}$ La unidad de inversión (UDI) es una unidad de cuenta cuyo valor es estimado por el Banco de México (el banco central del país) y se ajusta diariamente con la inflación.
}

unidades de inversión, es un swap que ofrece actualmente la SHF (inicialmente lo hacía el FOVI) a través de los intermediarios financieros. El costo de la cobertura se distribuye entre el deudor y el Gobierno Federal: el primero paga una prima de 71 puntos base, que junto con una línea de crédito bancario avalada por el Gobierno Federal viene generando un fondo para cubrir faltantes temporales de flujos y respaldar situaciones de crisis profundas. ${ }^{16}$ Este fondo está concebido para poder soportar un deterioro real del salario de $25 \%$ a 30 años. Si el deterioro fuese mayor, la SHF tendría pérdidas; si fuese menor, obtendría una utilidad. Este es un ejemplo práctico que combina la participación estatal con el compromiso de los beneficiarios de compartir el costo de esta suerte de seguro, agregando una prima a la tasa de interés que pagan al prestamista.

Otra acción a la que podría abocarse el Estado con miras a promover el funcionamiento de un mercado de créditos hipotecarios de amplia cobertura es la de asumir un papel activo como banca de segundo piso. La experiencia latinoamericana es reveladora de la ineficiencia del Estado como prestamista directo: ni los fondos disponibles han sido asignados a la población más necesitada ni la cobranza de esos créditos ha sido muy exitosa. En contraposición, los esquemas institucionales de banca de segundo piso, ya existentes en varios países de la región (Costa Rica, Ecuador, México y Perú, entre otros), pueden ser instrumentos más eficientes para allegar recursos a los originadores de crédito y para estimular la formación y consolidación de un mercado financiero de vivienda.

En Costa Rica, el Banco Hipotecario de la Vivienda (BANHVI) es una entidad financiera pública que funge de ente rector del Sistema Financiero Nacional para la Vivienda (SFNV) como banco de segundo piso. La estrategia seguida para poner en marcha el SFNV fue unir al subsidio una amplia capacidad de compra de hipotecas por parte del BANHVI, a fin de que los intermediarios financieros pudieran comprometerse en masivos financiamientos, mitigando los potenciales problemas de liquidez y de descalce de plazos. En los primeros años del SFNV, la capacidad de descuento de hipotecas del BanHVI no sólo constituyó una de las fuentes de recursos más importantes para las mutuales de ahorro y préstamo, sino también explicó buena parte de la dinámica del sistema. ${ }^{17}$ Sin embargo, en el decenio de

\footnotetext{
16 Véase Zepeda (2000, pp. 30-35).

${ }^{17}$ Entre 1989 y 1992 el BANHVI concretó un promedio anual de más de 7.000 operaciones de redescuento de hipotecas. Véase Zawadzki (1994, p. 40)
} 
1990 se agudizó la escasez de recursos para ejercer esta función y desde hace casi un decenio el BANHVI prácticamente la ha dejado, lo que ha hecho más difícil el logro de una actividad crediticia mayor, especialmente para sectores con capacidad de endeudamiento que son beneficiarios del subsidio.

Por su parte, en 1998 el Banco Ecuatoriano de la Vivienda (BEV) fue reestructurado y se convirtió en un banco de segundo piso, orientado a apoyar la construcción y financiamiento de viviendas mediante el refinanciamiento de las carteras hipotecarias de las instituciones financieras intermediarias (IFI) privadas, pero sin tener relación directa con los beneficiarios finales como antaño. Tras haber ejercido estas funciones durante algunos años, uno de los principales retos que debe encarar hoy el BEv como banco de segundo piso es el de ampliar sus operaciones de redescuento y reducir costos para convertirse en una fuente de recursos capaz de potenciar la oferta de créditos hipotecarios.

En México, la SHF maneja varios productos crediticios, ejerciendo el papel de banca de segundo piso. Entre ellos pueden mencionarse las líneas de crédito a los intermediarios financieros para la adquisición de viviendas, aunque dentro de algunos años esto dejará de tener vigencia. Luego de la crisis del tequila en 1994-1995, las llamadas sociedades financieras de objeto limitado (sofoles) fueron adquiriendo un papel preponderante como instituciones financieras de vivienda; hoy día canalizan casi el $96 \%$ de los recursos otorgados por la SHF, y lo que es más, vienen atendiendo a mercados que antes no tenían acceso a créditos hipotecarios de intermediarios financieros privados. ${ }^{18}$ Cabe señalar que, según la ley que la creó, la sHF mantendrá la facultad de otorgar préstamos solamente hasta el 12 de octubre del 2009; después sólo podrá influir en el mercado a través del otorgamiento de garantías. Una función que la sHF puede realizar y que no efectuaba su predecesor - el Fovi— es procurar que las sociedades financieras de objeto limitado se financien directamente, mediante líneas de crédito bancario o a través del mercado de valores, pero apoyadas con una garantía de pago oportuno otorgada por la SHF.

Este rol de banca de segundo piso se traduce, por ejemplo, en la extensión de líneas de crédito, incluyendo la contratación de créditos externos, un mecanismo de redescuento de hipotecas, y la emisión de títulos hipotecarios en el mercado de capital. Generalmente, por esta vía es posible movilizar hacia el mercado de

18 Véase Obregón (2001, pp. 49-56). créditos hipotecarios un volumen de recursos en condiciones más ventajosas de plazos y costos, que no solamente incentivan la participación de los prestamistas privados sino también permiten, en principio, abarcar a segmentos de la población con capacidad de pago más limitada.

Además de las vías antes mencionadas para concretar la actuación del Estado como banca de segundo piso, presentes en mayor o menor medida en varios países de la región, la tendencia a la formación de mercados secundarios de hipotecas — vital, como ya se ha dicho, para asegurar la transformación de plazos que requiere el financiamiento de la vivienda - también permite ampliar la participación del Estado como agente catalizador del mercado financiero habitacional. Hace muchos años, por ejemplo, en Chile le cupo al Estado desempeñar un papel gravitante como hacedor de mercados en la negociación de letras de crédito hipotecario. En el caso de los mercados de bonos securitizados con respaldo de hipotecas, puede ser importante lo que haga el Estado por impulsar la estandarización en el mercado primario de hipotecas sobre la base de incentivos para que los originadores y otros agentes participantes adhieran a ciertos estándares que faciliten la formación de una masa de hipotecas securitizables. Por ejemplo, desde 1998 el Banco Central de la República Argentina incentiva a los intermediarios financieros a utilizar un contrato estandarizado para el otorgamiento de créditos hipotecarios para vivienda, mientras que en México la SHF, en su papel de garante, está promoviendo la estandarización tanto de documentos como de procedimientos de generación y cobranza de créditos hipotecarios.

Asimismo, la provisión de garantías por parte del Estado a los títulos y valores que se emitan con respaldo de carteras hipotecarias, particularmente las que incluyan créditos de vivienda para deudores de menores ingresos, puede contribuir al mejoramiento crediticio de dichos instrumentos. Es lo que se pretende hacer en Colombia a través de la Titularizadora Colombiana; en México, por medio de la SHF, a la que se asigna una función preponderante como proveedor de seguros a emisiones respaldadas por hipotecas; y en Perú, por conducto del Fondo Mivivienda, cuya ley de creación fue reformada para permitirle garantizar títulos y valores relacionados con el financiamiento habitacional que emitan o gestionen las instituciones financieras o sociedades securitizadoras.

Por otro lado, puesto que el déficit habitacional en los sectores de menores ingresos es muchas veces de naturaleza cualitativa, estos sectores dan alta prioridad 
al mejoramiento de las viviendas existentes. Por lo tanto, sus necesidades de financiamiento para vivienda están relacionadas con créditos de menor valor, a plazos más cortos y no necesariamente con garantía hipotecaria. En tal sentido, conviene estimular alternativas de microfinanzas que sirvan para atender este tipo de necesidades de crédito. En la República Dominicana, por ejemplo, han surgido algunas iniciativas de otorgar microcréditos, a cargo de las asociaciones de ahorros y préstamos, para mejorar viviendas en barrios de bajos ingresos. Asimismo, el Banco Nacional de Fomento de la Vivienda y la Producción (BNV) creó un fondo de microfinanciamiento para mejorar y ampliar viviendas, cuyos recursos serán canalizados a través de organizaciones no gubernamentales que promuevan el microcrédito y de grupos solidarios con capacidad de penetración en las comunidades. Se fundamentará la solidez del financiamiento en la supervisión dirigida y permanente, y no tanto la existencia de garantías reales; se ofrecerán programas de financiamiento para la mejora y reparación de viviendas y, por ende, se proporcionarán créditos de bajo monto (1.500 a 2.000 dólares en promedio). También se apoyarán sistemas de autoconstrucción dirigida y de ayuda mutua, y se operará en condiciones de mercado, a fin de que los recursos existentes en el sector formal puedan ser aplicados en el sector informal. Aun cuando experiencias de este tipo son aún incipientes en la República Dominicana y en general en la región, el producto financiero descrito tiene un enorme mercado potencial; más aún, por tratarse de créditos a corto y mediano plazo, puede haber una mejor correspondencia entre modalidades tradicionales de captación y de colocación, y por el hecho de haber inversión previa en la vivienda, la relación crédito-garantía es más favorable, si la propiedad actúa como garantía.

Finalmente, siempre pensando en hacer más accesible el crédito habitacional a la población de escasos recursos, es importante diseñar productos que estimulen el ahorro previo para vivienda a través del sistema financiero y que permitan ampliar la base de clientes potenciales con la incorporación de grupos que tradicionalmente son rechazados por su incapacidad de acreditar ingresos permanentes. En Chile, por ejemplo, la exigencia de ahorro previo como requisito para acceder al subsidio estatal ha sido una poderosa herramienta para la formación de un volumen significativo de ahorros financieros de bajo monto. En México, a través de planes de aportes metódicos se puede construir un historial financiero que permite a las familias involucradas demostrar su capacidad de pago y, al mismo tiempo, cubrir la cuota inicial del crédito que posteriormente se otorgue. Más recientemente, en Perú se han puesto en marcha programas de ahorro similares como requisito para postular a los programas de subsidio directo y de créditos complementarios. Dichos programas no sólo contribuyen a identificar sino también a "calificar" a sujetos de crédito. Por esta vía se puede atraer al mercado de créditos hipotecarios a un amplio sector de la población que trabaja por cuenta propia y que constituye una porción significativa de la demanda potencial de vivienda.
Almarza, S. (2000): Evaluación de los recursos en la política habitacional, en G. Crespo, P. Gross y otros, Consulta sobre la política habitacional en Chile: informe final, Lima, Unión Interamericana para la Vivienda (UNIAPRAVI).

CEPAL (Comisión Económica para América Latina y el Caribe) (2001): Panorama social de América Latina, 2000-2001, LC/G.2138-P, Santiago de Chile, septiembre. Publicación de las Naciones Unidas, $\mathrm{N}^{\circ}$ de venta: S.01.II.G.141.

(2002): El crédito hipotecario y el acceso a la vivienda para los hogares de menores ingresos en América Latina, serie Financiamiento del desarrollo, $\mathrm{N}^{\circ}$ 122, LC/L.1779-P, Santiago de Chile, septiembre. Publicación de las Naciones Unidas, $\mathrm{N}^{\circ}$ de venta: S.02.II.G.94.

Forero, E. (2001): La financiación de vivienda en Colombia, documento presentado en el XX Congreso Nacional de FEDELONJAS "El futuro de la vivienda en Colombia" (Bogotá, D.C., junio de 2001).

Gonzales Arrieta, G. (1999): Acceso a la vivienda y subsidios habitacionales directos: experiencias latinoamericanas, Revista de la CEPAL, $\mathrm{N}^{\circ}$ 69, LC/G.2067-P, Santiago de Chile, diciembre.
González, G. (2001): Nuevos instrumentos de acceso a la vivienda en Chile: el leasing habitacional, en G.M. Gonzales Arrieta (comp.), Mercados de capitales y financiamiento de la vivienda: la securitización en Chile, Lima, Unión Interamericana para la Vivienda (UNIAPRAVI).

Hausmann, R. (1998): Perspectivas del financiamiento de vivienda en América Latina: una visión coyuntural y de largo plazo, Cuadernos, $N^{\circ} 179$, julio-septiembre, Lima, Unión Interamericana para la Vivienda (UNIAPRAVI).

Marez, M. (2000): Adapting risk management practices to the realities of the Mexican mortgage market, International Journal of Real Estate Finance, vol. 1, N ${ }^{\circ}$ 2, Washington, D.C., Societas, noviembre-diciembre.

Obregón, C. (2001): Las sofoles como alternativa de financiamiento para la vivienda en México, La consolidación de los mercados financieros de vivienda en América Latina, Lima, Unión Interamericana para la Vivienda (UNIAPRAVI).

Pardo, C. (1998): Housing financing in Chile: the experience in primary and secondary mortgage financing, documento presentado en la Conferencia del Banco Interamericano de 
Desarrollo "The development of mortgage securitization in Latin America and the Caribbean" (Washington, D.C., noviembre de 1998).

Renaud, B. (1997): Financial markets and the financing of social housing: a view from developing countries, documento presentado en la Conference on Social Housing Finance in the European Union (Nunspeet, Países Bajos, febrero de 1997).

Rojas, E. (1999): The long road to housing reform: lessons from the Chilean experience, Sustainable Development Department Best Practices Series, Washington, D.C., Banco Interamericano de Desarrollo (BID), julio.

Rojas, E. y M. Greene (1995): Reaching the poor: lessons from the Chilean housing experience, Environment \& Urbanization, vol. $7, \mathrm{~N}^{\mathrm{o}} 2$, Londres, Instituto Internacional para el Medio Ambiente y el Desarrollo (IIMAD), octubre.
Varela, J.G. (2001): Instrumentos de financiamiento habitacional en el mercado primario chileno: letras de crédito hipotecario y mutuos hipotecarios endosables, en G.M. Gonzales Arrieta (comp.), Mercados de capitales y financiamiento de la vivienda: la securitización en Chile, Lima, Unión Interamericana para la Vivienda (UNIAPRAVI).

Zawadzki, C. (1994): Nuevos modelos de financiamiento de vivienda en América Latina, Anales de la XXXI Conferencia Interamericana para la Vivienda, Lima, Unión Interamericana para la Vivienda (UNIAPRAVI).

Zepeda, M. (2000): Innovaciones en la originación y administración de créditos hipotecarios: el caso del FOVI de México, $L a$ vivienda y la gestión urbana: un desafío para el año 2000, Lima, Unión Interamericana para la Vivienda (UNIAPRAVI). 